Natvig, H. (1941). Skr. norske VidenskAkad. I. mat. naturu. Kl. 2, 226.

Osborn, T. W. B. \& Gear, J. H. S. (1940). Nature, Lond., 145, 974.

Otani, T. (1939). Orient. F. Dis. Infants, 25, I.

Pfannenstiel, W. \& Dotzer, W. (1940). Z. ImmunForsch. 99, 86.

Sabin, A. B. (1939). F. exp. Med. 69, 507.

Simola, P. E. \& Brunius, E. (1933). Biochem. Z. 258, 228.

Souto, A. B. \& Lima, C. (1938). C.R. Soc. Biol., Paris, 129, 763.

Spink, W. W., Agnew, S., Michelson, O. \& Dahl, L. (1942). F. Immunol. 44, 303.

Spink, W. W., Michelson, O. \& Agnew, S. (194I). F. clin. Incest. 20, 434.

Steinbach, M. M. \& Klein, S. J. (194I). Amer. Rev. Tuberc. 43, 403.

Tonutti, E. \& Matzner, K. H. (1938). Klin. Wschr. 17, 63.

Torrance, C. C. (1938). Amer. F. Path. 14, 632.

Willison, F. E. (1943). F. Immunol. 47, 409 .

Wilson, G. S. \& Miles, A. A. (1946). 'Topley \& Wilson's Principles of Bacteriology and Immunity, 3rd ed. London: Edward Arnold and Co.

Zilva, S. S. (1936). Biochem. Ұ. 30, 1419.

Zilva, S. S. (1937). Brit. F. exp. Path. 18, 449.

\title{
Diet and Disease of the Liver
}

\section{By L. E. GLYNN \\ Canadian Red Cross Memorial Hospital, Taplow, Maidenhead, Berks}

The nutritional approach to the study of disease has proved extremely fruitful, especially in the case of diseases of the liver. By the use of experimental diets, not only is a series of specific nutritional deficiency diseases produced, but valuable clues are obtained to the mechanism which underlies the development of many well recognized diseases whose aetiology has hitherto been quite obscure and not obviously nutritional. I refer in particular to liver cirrhosis and acute yellow atrophy. By carefully chosen diets one can deprive the experimental animal of remarkably specific food factors, and the results of such deprivation may be equally remarkable and specific. An insight is thus obtained into the normal function and structure, and an equally important insight into derangements of function and structure which constitute disease. Thus we are not only led to the elucidation of nutritional deficiency diseases as such, but to the elucidation of many diseases not hitherto so considered. For deficiency of some essential metabolite may well arise apart from its absolute deficiency in the diet. Deficiency is a relative state and may equally well arise from increased demand, from increased excretion or from some interfering metabolites, as from diminished intake, and it is gradually becoming apparent that many so-called idiopathic diseases, i.e. diseases of obscure aetiology, are the result of such a conditioned nutritional deficiency.

\section{Nutritional factors necessary for maintaining the normal state of the liver}

It has been recognized for many years that the appearance of the liver depends on the nutritional state of the individual. Starvation causes a rapid reduction in the weight of the liver, depletion of its glycogen, the loss of a considerable amount of its protein (Kosterlitz \& Campbell, r945) and some accumulation of fat. The increased susceptibility of the liver in this state to injury by chloroform has also been known for many years (Opie \& Alford, 1915). 
More recently two fundamentally distinct types of liver lesion have been produced by nutritional means in experimental animals, namely, fatty infiltration with its sequel, diffuse fibrosis, and acute yellow atrophy, more correctly described as massive hepatic necrosis (Himsworth \& Glynn, 1944a, $b$ ).

\section{Fatty infiltration of the liver}

The recent advances in our knowledge of the dietary factors affecting the hepatic metabolism of fat date from the observation that pancreatectomized dogs maintained by insulin develop severe fatty infiltration of the liver that is preventable by the feeding of lecithin (Hershey, 1930). Further factors preventing the deposition of fat and others favouring its deposition were subsequently discovered. The former were called lipotropic and the latter alipotropic (Best \& Lucas, 1943). The most important of the lipotropic factors are choline or substances which contain choline, such as lecithin, and the thioamino-acid methionine ('Tucker \& Eckstein, 1937). 'The lipotropic activity of choline results from an increased rate of synthesis of liver fat into a phospholipid such as lecithin, in which form it is conveyed to the depots in the adipose tissue. The lipotropic action of methionine results from its providing the body with a source of methyl groups for the endogenous formation of choline, since the mammalian body is incapable of synthesizing this organic radical (du Vigneaud, 1942). Since the principal source of methionine is protein of high biological value, and since choline too is found only in the more expensive types of food such as meat, eggs and milk, ill-off persons living on less expensive high-carbohydrate diets develop severe fatty infiltration of the liver.

This marked infiltration of fat, which may exceed $30 \%$ of the wet weight of the liver, undoubtedly impairs the normal functioning of the liver cells. Both the hippuric acid excretion and that of bromsulphalein are impaired in dogs on a diet low in choline, the excretion returning to normal when choline supplements are given (Hough, Monahan, Li \& Freeman, 1943). With long standing fatty infiltration, atrophic and degenerative changes supervene in the centrilobular cells. This is soon followed by fibrosis, which extends diffusely throughout the liver and at first tends to demarcate the Sabourin lobule, but soon the fibrous tissue extends between the liver cells within the lobule, thus obscuring and destroying the normal lobular architecture. Many of these isolated groups of cells then undergo concentric hyperplasia until the typical fine granular appearance of Laënnec's cirrhosis results.

The aetiological significance of the fatty infiltration in the evolution of experimental cirrhosis is well brought out by recent experiments (Glynn, Himsworth \& Lindan, 1948). Groups of rats were maintained on hypolipotropic diets, low in protein and containing different proportions of fat, from 4 to $50 \%$ by weight. Animals in all groups received the same number of calories and the same quantity of protein daily. It was found that there was a direct relation between the dietary level of fat and the degree of fatty infiltration, and between the latter and the rate and degree of development of cirrhosis.

The pathogenesis of this cirrhosis is not completely elucidated, but an important factor in its development is the impairment of the circulation that results from the 
compression of the sinusoids by the distended liver cells. This has been demonstrated by using rats maintained for only a few days on an alipotropic diet (Glynn et al. 1948). In such animals the fatty infiltration is irregularly distributed and perfusion of the liver in vivo by the injection of Indian ink into the spleen reveals the contrast between the well-injected normal areas and the poorly injected fatty areas. No doubt part of the functional impairment of the severely fatty liver results from this circulatory impairment.

Impairment of hepatic function leading ultimately to a cirrhosis similar to that following fatty infiltration may also result from other types of severe infiltration, e.g. cholesterol (Chalatow, 1914), glycogen (Kimmelstiel, 1933), kerasin (Epstein, 1924) and phospholipid (Thannhauser, 1940), which further suggests that the mechanical effect of the infiltration is of greater significance than the chemical nature of the infiltrating agent.

The anoxia produced by this circulatory impairment is of extreme importance, although the part played by the deprivation of other essential materials must not be overlooked. 'That anoxia alone can produce severe damage to the centrilobular cells was shown by McIver \& Winter (1943) and by Martin, Bunting \& Lowenhart (1916). Any increase in the basal metabolic rate might be expected to increase the susceptibility to anoxic damage and this probably explains in part the much higher incidence of hepatic necrosis and cirrhosis in thyrotoxic subjects (Cameron \& Karunaratne, r 935 ; McIver, 1942).

In consequence of the relationship demonstrated in animals between nutritional deficiency and the development of hepatic cirrhosis, attempts have been made to treat human cases by dietary means. Patek ( $1937-8)$, who was the pioneer in this field, used high-protein diets with large vitamin supplements. His encouraging results were largely confirmed by many workers using various combinations of diets high in protein and low in fat with supplements of yeast, choline, cystine and methionine (Patek \& Post, I941; Broun \& Muether, I942; Russakoff \& Blumberg, 1944). Best and his co-workers (Sellers, Lucas \& Best, 1948) tried to throw further light on this therapeutic procedure by studying the effect of lipotropic agents on the cirrhosis produced in rats by repeated exposure to carbon tetrachloride. They found that with diets deficient in lipotropic factors none of the animals showed any improvement in their cirrhosis. When, however, 'adequate amounts of pure choline chloride or DL-methionine were added to the basal hypolipotropic diet a remarkable improvement in the gross appearance of the livers was noted within two or three weeks'. High-protein diets which contained an adequate amount of naturally occurring methionine produced equally favourable results. It must, however, be remembered that the cirrhosis in these experimental animals was in the reversible stage (Cameron \& Karunaratne, 1936) that is, that in the absence of further toxic insult the scarring and deformity would gradually disappear. This surely implies that the blood supply to the liver was still adequate for its normal metabolism provided that further compression by fat-laden liver cells was avoided by adequate intake of lipotropic agents. A stage, however, is reached in the evolution of experimental cirrhosis, and probably also of cirrhosis in man, in which the hepatic scarring is irreversible. It has been suggested (Editorial, I948) that this stage corresponds to a degree of circulatory impairment in which the 
blood supply to the liver is now inadequate for its normal metabolism, and that since this circulatory impairment results from fibrous scarring and not from sinusoidal compression, the condition is no longer amenable to therapy by lipotropic agents.

\section{Massive hepatic necrosis}

The second of the hepatic lesions that have been attributed to dietary deficiency is massive hepatic necrosis. This lesion was almost certainly first produced experimentally by Weichselbaum (1935), using diets low in thioamino-acids, but the lesions were considered to be haemorrhages and not recognized as necroses. Györgi \& Goldblatt (1939) were the first to appreciate the necrotic nature of the lesions, but they considered them to be a more severe and acute manifestation of the cirrhosis that results from severe and prolonged fatty infiltration. Himsworth \& Glynn (1944a,b), however, were able to differentiate the two lesions quite conclusively and to produce each independently of the other.

Massive necrosis of the liver in rats does not occur if the dietary level of methionine or cystine exceeds $40 \mathrm{mg}$. rat daily. A dietary intake of less than $10 \mathrm{mg}$. frequently results in a fatal attack of acute yellow atrophy, usually between the 2oth and 5 oth day on the diet. Other factors, as yet incompletely understood, affect the susceptibility of the animals to methionine deficiency.

Rao (1948) has particularly called attention to variations in strain susceptibility, in the nature of yeast and vitamin supplements, in the intestinal flora and in climatic conditions, as possible explanations of the different results obtained in different laboratories using apparently similar techniques. One factor of great importance is vitamin $\mathrm{E}$, and it is now established that massive hepatic necrosis will not occur in rats on a diet low in thioamino-acids unless there is a simultaneous deficiency in dietary tocopherol (Györgi, 1947). The variability of the results even in the presence of this dual deficiency has suggested that some infective factor is also necessary. Neither Himsworth \& Glynn (1944a,b) nor Györgi \& Goldblatt (1942) were able to find any evidence of this. There is, however, a considerable body of evidençe indicating that in man a low-protein hypolipotropic diet greatly increases the incidence of massive hepatic necrosis in cases of infective hepatitis (Seyfarth, I921; Strumpell, I921; Fox, Manso, Penna \& Pará, I942; Himsworth, 1947).

A remarkable tendency of massive necrosis to favour the left half of the liver and relatively to spare the right half has been observed repeatedly in man ('Turnbull, I917; Stewart, 1917; Lucké, 1944), and in the rat (Himsworth \& Glynn, 1944a,b). This is probably attributable to a peculiarity of the blood flow in the portal vein, as a result of which blood from the superior mesenteric vein passes to the right lobes, whilst blood from the spleen and left half of the colon passes to the left lobes. This streamline effect was first suggested by Sérégé (1902), subsequently demonstrated in dogs by Copher \& Dick (1928), and confirmed in rats by Himsworth \& Glynn ( $1944 a, b$ ). By injecting Indian ink into the spleen of normal anaesthetized rats it can be readily shown that those parts of the liver particularly involved in partial massive necrosis coincide remarkably with the areas supplied through the splenic vein. Since the products of protein digestion, including presumably the thioamino-acids, are almost entirely 
absorbed from the small intestine through the superior mesenteric tributary of the portal vein, it is hardly surprising that hepatic lesions resulting from thioamino-acid deficiency should favour those lobes supplied through the splenic tributary.

It might be thought that undue stress has been laid upon this distribution of the lesions in partial massive necrosis. This, however, is so striking in both man and the experimental animal that it seems highly probable that a similar mechanism underlies both. Whereas the lesion in the rat is the result of an absolute nutritional deficiency, it is doubtful whether the protein intake of man ever falls low enough in this country to account for the rare cases of acute yellow atrophy. In less well-off communities, however, massive hepatic necrosis is by no means rare, and its high incidence in parts of Africa and elsewhere shows a close correlation with protein intake. As with other nutritional deficiencies, however, deficiency is a relative concept, and what might otherwise prove to be an adequate intake may well become inadequate as a result of malabsorption, destruction in the intestine and elsewhere, excessive excretion, metabolic interference or increased demand associated with increased metabolic rate. Deficiency resulting from one or other of these factors may be termed 'conditioned' and probably accounts for the majority of cases in western Europe and the United States in association with pregnancy, infective hepatitis and poisoning by such substances as trinitrotoluene and cinchophen.

\section{Diet and susceptibility to liver poisons}

Hepatic dysfunction associated with gross liver damage may result from the action upon the liver of a host of substances having little in common but their hepato-toxic qualities. Analysis of the lesions produced by ingestion or subcutaneous injection of such substances (Himsworth \& Glynn, 1944 $b$ ) shows that they fall into two main categories:

(I) those which rapidly and consistently produce a liver lesion, usually a uniformly distributed zonal necrosis;

(2) those which only rarely and irregularly produce hepatic lesions in the exposed individual, the lesion in most cases conforming to the massive rather than to the zonal type.

Typical of the first category are carbon tetrachloride and chloroform; typical of the second are trinitrotoluene and cinchophen. That circulatory and nutritional factors are of importance in determining the incidence and distribution of the lesions associated with the second group of substances has already been mentioned (Himsworth \& Glynn, 1942). That susceptibility to poisons of the first group is dependent upon nutrition has also been recognized for many years since Opie \& Alford (1915) demonstrated the adverse influence of a high fat intake on the susceptibility of animals to chloroform. Much still remains to be clarified about the effect of diet upon susceptibility to liver poisons, but the protective value of protein and the thioamino-acids has been definitely established by Whipple and his collaborators for chloroform poisoning in dogs (Miller \& Whipple, r940; Miller, Ross \& Whipple, 1940). With reference to the circulation, however, little definite has been established except that with many poisons 
anoxia increases susceptibility, whereas a raised tension of oxygen in the inspired air gives some increased protection (Goldschmidt, Ravdin \& Lucké, 1937). Recently, however, Wakim \& Mann (1942) have drawn attention to the impaired intralobular hepatic circulation that occurs in carbon tetrachloride poisoning, and Glynn \& Himsworth (1948) have shown that the degree of circulatory impairment and resulting anoxia may itself be sufficient to account for the characteristic centrilobular distribution of the lesions found. They suggest that swelling of the liver cells with sinusoidal compression and hence impaired nutrition and oxygenation is the characteristic reaction of the liver to that class of liver poisons which produces centrilobular zonal necrosis, and that impairment of liver function in such cases is not so much the result of liver injury as impairment of the intrahepatic circulation.

Impairment of hepatic function and demonstrable injury may result from any circulatory disturbance, as in congestive cardiac failure or from obstruction of portal or hepatic arterial branches. Whereas in all animals investigated interference with the venous outflow leads to centrilobular necrosis and atrophy, as in the 'nutmeg' liver of congestive failure, the results of obstruction of the portal vein or hepatic artery vary with the species and the individual. Mcilichael (1937) has shown, for example, that whereas in rabbits ligation of a branch of the hepatic artery leads to infarction, in cats the only result may be some slight centrilobular degeneration. Apparently the factor of paramount importance is the oxygen supply to the liver cells. In rabbits most of the oxygen consumed by the liver is brought through the hepatic artery, but in cats the greater part of the oxygen is obtained through the portal vein; hence arterial ligature leads to infarction in rabbits but not in cats. The condition of the circulation in the individual animal is also of importance. Thus if the blood pressure in the cat is allowed to fall, reducing the portal blood flow, arterial ligation then leads to infarction.

There is much difference of opinion about the results of ligation of a branch of the portal vein. In the older literature sepsis and thrombosis account for many of the necroses obtained. In the rabbit, and probably in man, an uncomplicated ligation of a branch of the portal vein does not lead to infarction but to a progressive atrophy till in the area affected every liver cell has disappeared and only the fibrous framework and portal structures remain (Rous \& Larimore, 1920). Simultaneously, in otherwise healthy animals, a compensatory hyperplasia occurs in the remaining liver tissue.

Biliary obstruction may also lead to considerable impairment of hepatic function and ultimately of structure. In many cases part at least of these disturbances is to be attributed to the supervention of infection. In some cases, however, even in the absence of infection, distinct damage results (Cameron \& Oakley, 1932), leading eventually to the scarred granular liver of obstructive biliary cirrhosis. The interference with function that results from biliary obstruction is not only reflected in the pigment metabolism of the liver but even in the early stages probably affects most of its activities. This is well illustrated in the classical experiment of Rous \& Larimore (1920), in which the hypertrophy of the right lobe of the liver that occurs in rabbits after ligation of the left branch of the portal vein is completely inhibited by simultaneous ligation of the right hepatic duct. It also accounts for the unreliability of liver function tests in differentiating obstructive from other kinds of jaundice, except in the very early stages. 


\section{Conclusions}

In this paper I have tried to emphasize the apparent diversity of the methods by which the function and integrity of the liver may be adversely affected; but the closer analysis of the methods considered has tended to show that a metabolic uniformity or similarity underlies the majority. This uniform metabolic impairment is a deprivation of essential nutrients, including oxygen, of the actively metabolizing parenchymal cells. To it may be attributed the lesions resulting from such diverse disturbances as fatty infiltration, chloroform poisoning, thyrotoxicosis, malnutrition and acute yellow atrophy of trinitrotoluene workers. Maegraith, Andrews \& Gall (1947) have recently drawn attention to a similar mechanism underlying the hepatic lesions in severe malaria and in shock. Although in each case subsidiary influences no doubt contribute and account for the characteristic differences, between the resultant lesions, if such exist, the essential factor is a metabolic deficiency resulting from a quantitative or qualitative deficiency in the blood supply. An appreciation of this mechanism opens new fields in prophylaxis and therapy.

\section{REFERENCES}

Best, C. H. \& Lucas, C. C. (I943). Vitamins and Hormones, I, I.

Broun, G. O. \& Muether, R. O. (1942). F. Amer. med. Ass. $118,1403$.

Cameron, G. R. \& Karunaratne, W. A. E. (1935). J. Path. Bact. 41, 267.

Cameron, (i. R. \& Karunaratne, W. A. E. (1936). F. Path. Bact. 42, I.

Cameron, G. R. \& Oakley, C. L. (1932). F. Path. Bact. 35, 769.

Chalatow, S. S. (1914). Beitr. path. Anat. 57, 85.

Copher, G. H. \& Dick, B. .M. (1928). Arch. Surg. 17, 408.

Editorial (1948). Brit. med. F. i, 1089.

Epstein, E. (1924). Virchouts Arch. 253, 157.

Fox, J. P., Manso, C., Penna, H. A. \& Pará, M. (1942). Amer. J. Hyg. 36, 68.

Glynn, I. E. \& Himsworth, H. P. (1948). Clin. Sci. 6, 235

Glynn, L. E., Himsworth, H. P. \& Lindan, O. (1948). Brit. Y. exp. Path. 29 , I.

Goldschmidt, S., Ravdin, I. S. \& Lucké, B. (r937). F. Pharmacol. 59, 1.

Györgi, P. (1947). In Transactions of the Sixth Conference on Liver Injury, p. 67. New York: Josiah Macy Jr. Foundation.

Györgi, P. \& Goldblatt, H. (1939). J. exp. Med. 70, I85.

Györgi, P. \& Goldblatt, H. (1942). Э. exp. Med. 75, 355

Hershey, J. M. (1930). Amer. F. Physiol. 93, 657.

Himsworth, H. P. (1947). Lectures on the Liver and its Diseases. Oxford: Blackwell Scientific Publications.

Himsworth, H. P. \& Glynn, L. E. (1942). Clin. Sci. 4, 421.

Himsworth, H. P. \& Glynn, L. E. (r944a). Clin. Sci. 5, 93.

Himsworth, H. P. \& Glynn, L. E. $(1944 b)$. Lancet, 246, 457.

Hough, V. H., Monahan, E. P., Li, T. W. \& Freeman, S. (1943). Amer. F. Phy'siol. 139, 642.

Kimmelsticl, P. (1933). Beitr. path. Ariat. 95, 1.

Kosterlitz, H. W. \& Campbell, R. M. (1945). Nutr. Abstr. Rev. 15, I.

Lucké, B. (1944). Amer. F. Path. 20, 47 I.

McIver, M. A. (1942). Surgery, 12, 654.

Mclver, M. A. \& Winter, M. A. (1943). Arch. Surg. 46, 171.

McMichael, J. (1937), Quart. F. exp. Physiol. 27, 73.

Maegraith, B., Andrews, W. H. H. \& Gall, D. (1947). Lancet, 253, $78 \mathrm{r}$.

Martin, G. H., Bunting, C. H. \& I owenhart, A. S. (1916). F. Pharmacol. 8, 112.

Miller, L. I. \& Whipple, G. H. (1940). Amer. F. med. Sci. r99, 204.

Miller, L. L., Ross, J. F. \& Whipple, G. H. (1940). Amer. F. med. Sci. 200, 739.

Opie, E. I. \& Alford, L. B. (1915). F. exp. Med. 21, 1.

Patek, A. J. Jr. (1937-8). Proc. Soc. exp. Biol., N.Y., 37, 329.

Patek, A. J. Jr. \& Post, J. (1941). F. clin. Invest. 20, 481 .

Rao, M. V. R. (1948). Nature, Lond., r6r, 446.

Rous, P. \& Larimore, I.. D. (1920). Y. exp. Med. 31, 600. 
Russakoff, A. H. \& Blumberg, H. (I944). Ann. intern. Med. 21, 848.

Sellers, E. A., Lucas, C. C. \& Best, C. H. (1948). Brit. med. F. i, 1061.

Sérégé, H. (1902). C.R. Soc. Biol., Paris, 54, 200.

Seyfarth, C. (1921). Dtsch. med. Wschr. 47, 1222.

Stewart, M. J. (1917). Proc. R. Soc. Med. ro, ro.

Strumpell, A. (1921). Dtsch. med. Wschr. 47, 1219.

Thannhauser, S. J. (1940). Lipidoses, Diseases of Cellular Metabolism. Oxford: University Press.

Tucker, H. F. \& Eckstein, H. C. (1937). F. biol. Chem. 121, 479.

Turnbull, H. M. (1917). Proc. R. Soc. Med. Io, 47.

Vigneaud, V. du (1942). Harvey Lect. 43, 39.

Wakim, K. G. \& Mann, F. C. (1942). Arch. Path. 33, 198.

Weichselbaum, T. E. (1935). Quart. F. exp. Physiol. 25, $3^{6} 3$.

\title{
Nutrition and Disease in Veterinary Research
}

\author{
By H. H. GREEN \\ Veterinary Laboratory, Ministry of Agriculture, Weybridge, Surrey
}

\section{Introduction}

The invitation to read a paper on nutrition in relation to veterinary research was accompanied by a warning from the Secretary of the Scottish Committee to keep off 'deficiency diseases' per se, to shun any topics discussed before the Society in the past, to try to deal with indirect rather than direct associations between diseases of the larger domesticated animals and their food, to be as pastoral as possible by dwelling mainly on ruminants, and to try to make the paper read like a novelette.

This behest rules out vitamin deficiencies, common enough in poultry reared on the intensive system and in indoor pigs before reaching bacon weight, although rare in grazing animals. It also rules out deficiencies of major mineral elements such as phosphorus, as manifested in aphosphorosis of ruminants (Theiler \& Green, $193 \mathrm{I}-2$ ), and of minor minerals or trace elements (Green, I944) such as cobalt, lack of which was first established in Australasia but is now well recognized in certain sheep-rearing pastures in Britain. It does not rule out injurious minor elements entirely, but the most interesting British example, the molybdenosis of central Somerset, is excluded by its earlier discussion before the society by Ferguson (1944). It leaves open the vast topic of pasture plants injurious to livestock in virtue of toxic principles, ranging from poisons in the conventional sense of causing death rapidly, to photosensitizing substances producing diseases such as 'geeldikkop' in South Africa or 'yellowses' in Scotland, or unidentified toxins with a trigger action setting up a sequence of pathological changes terminating in clinical symptoms and death so long after ingestion that the origin of disaster is obscure, as in 'gousiekte' (caused by eating Vangueria pygmoeum) in South Africa where 'trekking sheep' spending only a day or two on one pasture may die of progressive myocarditis a month or two later on another. But such a topic is not what the Committee had in mind, and serves only to indicate some of the problems which differentiate the spheres of activity of medical and veterinary research workers. 